\title{
Do we have a limit for retrograde intrarenal surgery for solitary kidney stone?
}

\author{
Bulent Kati, Eyyup Sabri Pelit, Mehmet Demir, Ismail Yagmur, Adem Tuncekin, Halil Ciftci \\ Harran University, Faculty of Medicine, Urology Department, Sanliurfa, Turkey.
}

\begin{abstract}
Summary Objective: The management of urolithiasis in patients with a solitary kidney is challenging for urologists. This study aimed to evaluate the safety of retrograde intrarenal surgery (RIRS) in the treatment of stones in patients with solitary kidney and to reply to the question if there is any limit for this surgery.

Methods: Between January 2016 and December 2019, we enrolled 52 patients who had a solitary kidney and underwent RIRS. We collected data on preoperative patient characteristics, stone dimensions, and postoperative outcomes. Stone size, duration of operation, duration of fluoroscopy, type of anesthesia, and degree of surgical complication were evaluated retrospectively. Surgeries performed in less and more than 60 minutes and with and without complications were compared.

Results: A total of 52 patients with a kidney stone and a solitary kidney were evaluated. The mean stone size was $14 \pm 0.4 \mathrm{~cm}$ and surgical success rate was $87.3 \%$. In our study, 13 patients (24.5\%) had grade 1 minor complications, and none required a blood transfusion. The mean operation time was $51.9 \pm 17.3$ minutes. The postoperative creatinine value increased in 6 patients. The duration of operation in the group with complications was significantly higher than that in the group without complications. In patients who underwent an operation lasting $\geq$ 60 minutes, stone size, fluoroscopy time, and complication rate were significantly higher than in patients who underwent an operation lasting $\leq 60$ minutes. Conclusion: Our opinion is to be careful in patients with a solitary kidney with a big stone and we recommend assigning these procedure to experienced hands for not exceeding 60 minutes in one session.
\end{abstract}

KEY WORDS: Renal stone; Ureteroscopy; Retrograde intrarenal surgery; Complication; Solitary kidney.

Submitted 3 June 2021; Accepted 27 June 2021

\section{INTRODUCTION}

Due to recent advances in endourology, increases have been made in the success of surgical treatment of kidney stones as well as of the variety of complications that may develop. Minimally invasive surgery for kidney stones is particularly important for patients with renal failure or with solitary kidney. Extracorporeal shock wave lithotripsy (ESWL) treatment is a minimally invasive option that is frequently applicable due to its safety and success rate (1). However, since complications that may develop after ESWL in patients with solitary kidney may be more severe and require urgent intervention, ESWL is far from being the first option in such patients without pre-stenting (2). In recent years, the advent of medical engineering has increased the suitability of surgical instruments used for the urinary system. In general, retrograde intrarenal surgery (RIRS) has been performed successfully and safely in patients with kidney stones (3). In patients undergoing RIRS, minor and major complications may occur due to the operator's surgical experience, the patients' unique situations and technical equipment. Complications can be treated palliatively but in patients with solitary kidneys, they should be considered more serious (4-5), although many studies have suggested that this surgery can be performed safely in solitary kidneys (6-7).

We collected data to evaluate surgical outcomes and to identify limits of RIRS for safe treatment of these patients.

\section{MATERIALS AND METHODS}

This study was approved by the local ethics committee at our university. We retrospectively reviewed 52 patients with solitary kidneys who were treated with RIRS for renal stones between January 2016 and December 2019 including patients who were older than 18 years of age and were without any additional chronic diseases. The pre-operative urine cultures of all patients were confirmed to be negative. The stone burden was assessed by obtaining the stone's length, which was calculated according to the European Association of Urology guidelines. The RIRS procedures were performed by the same surgical team using a 9.5 F access sheath and the same flexible ureteroscope (Karl Storz ${ }^{\mathrm{TM}}$ Germany). A double J stent was used in patients who were unable to have an access sheath inserted and the surgery was postponed for 3-4 weeks later. The stones were broken using a Holmium YAG laser device (Sphinx Xjr ${ }^{\mathrm{TM}}$, Germany) with a force of 6-18 Kw. The anaesthesia type was evaluated in conjunction with the anaesthesiologist who performed high spinal or general anaesthesia according to the condition of the patient. Serum creatinine levels were evaluated preoperatively, at one day postoperatively and at one-week follow-up. Any surgical complications in the patients were assessed using a modified Satava Classification System (SCS). The stone sizes, duration of operation, duration of fluoroscopy, type of anaesthesia, and degree of surgical complications were evaluated retrospectively. Operations performed in less or more than 60 minutes were compared to set a time limit for risk of complication. 


\section{Statistical analysis}

Mean, standard deviation, median, range, frequency and ratio values were used in the descriptive statistics of the data. The distribution of the variables was measured with the Kolmogorov-Smirnov test. An independent sample ttest and the Mann-Whitney $U$ test were used to analyse the quantitative independent data.

In the analysis of dependent quantitative data, the Wilcoxon test was used. A chi-square test was used to analyse the qualitative independent data. For the data analysis, the Statistical Package for the Social Sciences (SPSS), version 22.0, was used.

\section{Results}

Fifty-two stone patients with solitary kidney were evaluated before and after surgery (Table 1).

The solitary kidneys were congenital in 15 cases (28.3\%), caused by a previous contralateral nephrectomy in 21 cases $(39.6 \%)$ and caused by a non-functioning contralateral unit in 16 cases (32.1\%). The postoperative follow-up period was approximately 3 months.

Our surgical success rate was $87.3 \%$. Residual stones less than $4 \mathrm{~mm}$ were considered clinically insignificant and were evaluated by non-contrast computerized tomography (CT) after postoperative double J stent extraction. Double J stents were removed after an average of $25 \pm 7.3$ days in patients without additional intervention. Stone location was the lower pole of the kidney in $22(42.3 \%)$ patients, lower pole and pelvis or middle pole in $16(30 \%)$ patients, renal pelvis in 10 patients and upper pole in 4 patients. Mean age, sex and kidney side distribution and mean stone size in patients with and without complications did not differ significantly ( $p>0.05)$ (Table 2).

The duration of surgical time in the group with complications was significantly higher than in the group without complications $(\mathrm{p}<0.05)$.

There was no significant difference in the duration of fluoroscopy time in the group with and without complications. There was no significant difference $(p>0.05)$ of anaesthesia type in the group with and without complications (Table 2).

The preoperative creatinine value was not significantly different $(p>0.05)$ in patients with or without any complications. In the group with complications, the postoperative increase of serum creatinine was higher than the value recorded in the group without complications $(\mathrm{p}<0.05)$ (Table 2). Mean age and sex, anaesthesia type and kidney side distribution of the patients were not significantly different between the groups in terms of operation time $(\mathrm{p}<0.05)$.

In the group with operation time $\geq 60$ min groups, stone size (Figure 1), duration of fluoroscopy time and any complication rate (Figure 2) were significantly higher than in the group with operation time was $\leq 60 \mathrm{~min}$ $(\mathrm{p}<0.05)$ (Table 3).
Table 1.

General characteristics of patients with solitary kidney stones.

\begin{tabular}{|c|c|c|c|}
\hline \multirow{2}{*}{\multicolumn{2}{|c|}{$\overline{\text { Age }}$}} & \multirow{2}{*}{$\begin{array}{cc}\text { Min-max } & \text { Median } \\
3.0-84.0 & 45.5\end{array}$} & \multirow{2}{*}{$\frac{\text { Mean + s.d. } / \mathbf{n}-\%}{45.3 \pm 17.9}$} \\
\hline & & & \\
\hline Gender & $\begin{array}{l}\text { Female } \\
\text { Male }\end{array}$ & & $\begin{array}{ll}22 & 42.3 \% \\
30 & 57.7 \%\end{array}$ \\
\hline$\overline{\text { Side }}$ & $\begin{array}{l}\text { Right } \\
\text { Left }\end{array}$ & & $\begin{array}{ll}25 & 48.1 \% \\
27 & 51.9 \% \\
\end{array}$ \\
\hline Kidney stone size (c & & $0.8-2.2 \quad 1.3$ & $1.4 \pm 0.4$ \\
\hline $\begin{array}{l}\text { Operation time (min } \\
\text { Anesthesia Type }\end{array}$ & $\begin{array}{l}<60 \\
\geq 60\end{array}$ & $15.0-90.0 \quad 50.0$ & $\begin{array}{cc}50.1 & \pm 17.3 \\
33 & 63.5 \% \\
19 & 36.5 \% \\
\end{array}$ \\
\hline Floroscopy time (sec & & $5.0-95.0 \quad 45.0$ & $\begin{array}{ll}42.0 & 21.8\end{array}$ \\
\hline Anesthesia Type & $\begin{array}{l}\text { General } \\
\text { Spinal }\end{array}$ & & $\begin{array}{ll}15 & 28.8 \% \\
37 & 71.2 \% \\
\end{array}$ \\
\hline Complication & $\begin{array}{l}(-) \\
(+)\end{array}$ & & $\begin{array}{ll}40 & 76.9 \% \\
12 & 23.1 \%\end{array}$ \\
\hline $\begin{array}{l}\text { Minor complication } \\
\text { Major complication }\end{array}$ & $\begin{array}{l}\text { rade 1) } \\
\text { grade 1) }\end{array}$ & & $\begin{array}{cc}1.1 & 21.2 \% \\
2 & 3.8 \%\end{array}$ \\
\hline Pre-op serume creat & ine (mg/dL) & $0.70 \pm 3.00 \quad 1.20$ & $1.28 \pm 0.55$ \\
\hline Post-op serume cred & nine (mg/dL) & $0.40-8.20 \quad 1.00$ & $1.47 \pm 1.54$ \\
\hline Creatinine difference & $\mathrm{mg} / \mathrm{dL})$ & $-1.50-6.60 \quad-0.10$ & $0.19 \pm 1.55$ \\
\hline
\end{tabular}

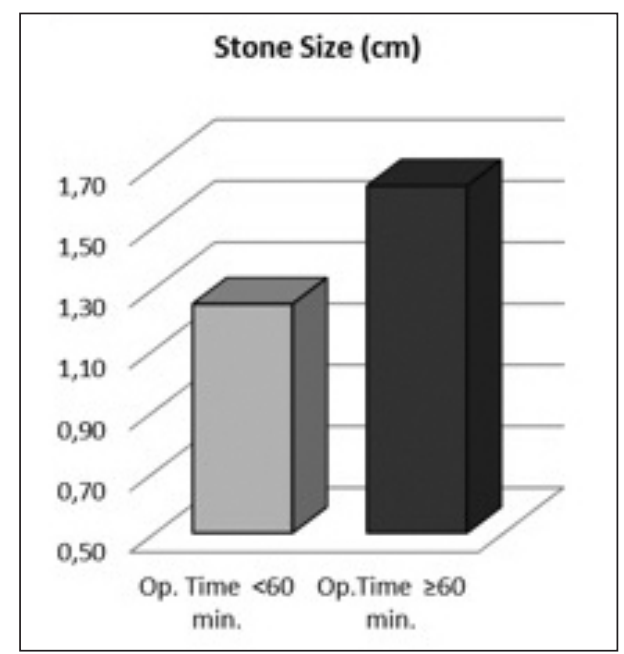

Figure 1. Relationship between stone size and operation time.

\section{Figure 2.}

Relationship between operation time and complications.

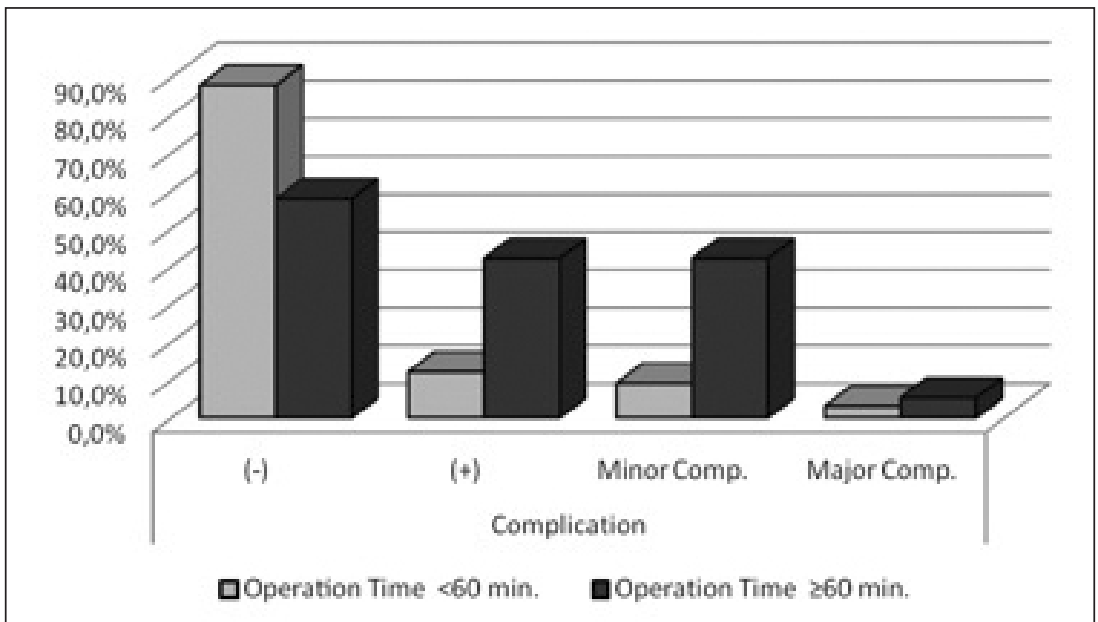


Table 2.

Comparison of patients with complications (minor or major) and without complications after RIRS.

\begin{tabular}{|c|c|c|c|c|c|}
\hline & \multicolumn{2}{|c|}{ Complication (-) } & \multicolumn{2}{|c|}{ Complication (+) } & \multirow[b]{2}{*}{$\mathbf{P}$} \\
\hline & Mean \pm s.s. $/ \mathrm{n}-\%$ & Median & Mean \pm S.S. $/ \mathrm{n}-\%$ & Median & \\
\hline$\overline{\text { Agge }}$ & $45.8 \pm 18.9$ & 45.5 & $43.8 \pm 14.7$ & 45.5 & $0.735^{t}$ \\
\hline $\begin{array}{ll}\text { Gender } & \text { Female } \\
& \text { Male }\end{array}$ & $\begin{array}{ll}16 & 42.4 \% \\
24 & 57.6 \%\end{array}$ & & $\begin{array}{ll}6 & 50.0 \% \\
6 & 50.0 \%\end{array}$ & & $0.539 x^{2}$ \\
\hline $\begin{array}{ll}\text { Side } & \begin{array}{l}\text { Right } \\
\text { Left }\end{array}\end{array}$ & $\begin{array}{ll}19 & 54.5 \% \\
21 & 45.5 \%\end{array}$ & & $\begin{array}{ll}6 & 50.0 \% \\
6 & 50.0 \%\end{array}$ & & $0.879 X^{2}$ \\
\hline Stone size (cm) & $1.3 \pm 0.4$ & 1.1 & $1.6 \pm 0.4$ & 1.5 & $0.099 \mathrm{~m}$ \\
\hline Operation time (min.) Süresi Dk & $46.8 \pm 15.1$ & 45.0 & $61.3 \pm 19.4$ & 60.0 & $0.010^{t}$ \\
\hline Floroscopy time (min.) & $39.3 \pm 20.8$ & 40.0 & $51.1 \pm 23.4$ & 52.5 & $0.100^{t}$ \\
\hline $\begin{aligned} \text { Anesthesia Type } & \text { General } \\
& \text { Spinal }\end{aligned}$ & $\begin{array}{ll}11 & 27.5 \% \\
29 & 72.5 \%\end{array}$ & & $\begin{array}{ll}4 & 33.3 \% \\
8 & 66.7 \%\end{array}$ & & $0.696^{x^{2}}$ \\
\hline $\begin{array}{l}\text { Serum creatinine }(\mathrm{mg} / \mathrm{dL}) \\
\text { Pre-op }\end{array}$ & $1.23 \pm 0.44$ & 1.20 & $1.42 \pm 0.83$ & 1.15 & $0.810^{\mathrm{m}}$ \\
\hline Post-op & $1.03 \pm 0.43$ & 0.90 & $2.93 \pm 2.72$ & 2.05 & $0.005 \mathrm{~m}$ \\
\hline $\begin{array}{l}\text { Preop-postop difference } \\
\text { In-group difference (p) }\end{array}$ & $\begin{array}{c}-0.20 \pm 0.61 \\
0.052 w\end{array}$ & -0.10 & $\begin{array}{c}1.52 \pm 2.70 \\
0.109 w\end{array}$ & 0.40 & $0.014 \mathrm{~m}$ \\
\hline
\end{tabular}

Table 3.

Comparison of RIRS cases above and below 60 minutes of operation time.

\begin{tabular}{|c|c|c|c|c|c|c|}
\hline & & \multicolumn{2}{|c|}{ Operation time $<60 \mathrm{~min}$. } & \multicolumn{3}{|c|}{ Operation time $\geq 60 \mathrm{~min}$. } \\
\hline & & Mean \pm s.s. $/ \mathrm{n}-\%$ & Median & Mean \pm S.s. $/ \mathrm{n}-\%$ & Median & $P$ \\
\hline \multicolumn{2}{|l|}{$\overline{\text { Age }}$} & $44.8 \pm 17.8$ & 41.0 & $46.2 \pm 18.6$ & 52.0 & $0.798^{t}$ \\
\hline Gender & $\begin{array}{l}\text { Female } \\
\text { Male }\end{array}$ & $\begin{array}{ll}14 & 42.4 \% \\
19 & 57.6 \%\end{array}$ & & $\begin{array}{cr}8 & 42.1 \% \\
11 & 57.9 \%\end{array}$ & & $0.982^{x^{2}}$ \\
\hline Side & $\begin{array}{l}\text { Right } \\
\text { Left }\end{array}$ & $\begin{array}{ll}18 & 54.5 \% \\
15 & 45.5 \%\end{array}$ & & $\begin{array}{cr}7 & 36.8 \% \\
12 & 63.2 \%\end{array}$ & & $0.219 x^{2}$ \\
\hline \multicolumn{2}{|l|}{ Stone size (cm) } & $1.2 \pm 0.4$ & 1.0 & $1.6 \pm 0.4$ & 1.8 & $0.003^{\mathrm{m}}$ \\
\hline \multicolumn{2}{|c|}{ Fluoroscopy time (min.) } & $31.4 \pm 15.1$ & 30.0 & $60.4 \pm 19.4$ & 60.0 & $0.000^{t}$ \\
\hline Anesthesia Type & $\begin{array}{l}\text { General } \\
\text { Spinal }\end{array}$ & $\begin{array}{cc}7 & 21.2 \% \\
26 & 78.8 \%\end{array}$ & & $\begin{array}{cr}8 & 42.1 \% \\
11 & 57.9 \%\end{array}$ & & $0.109^{x^{2}}$ \\
\hline Complication & $\begin{array}{l}(-) \\
(+)\end{array}$ & $\begin{array}{cc}29 & 87.9 \% \\
4 & 12.1 \%\end{array}$ & & $\begin{array}{rr}11 & 57.9 \% \\
8 & 42.1 \%\end{array}$ & & $0.013^{x^{2}}$ \\
\hline \multicolumn{2}{|c|}{ Minor complication } & $3 \quad 9.1 \%$ & & $8 \quad 42.1 \%$ & & $0.005^{x^{2}}$ \\
\hline \multicolumn{2}{|c|}{ Major complication } & $13.0 \%$ & & $1 \quad 5.3 \%$ & & $0.687 x^{2}$ \\
\hline \multicolumn{2}{|c|}{ Serum creatinine (mg/dL) } & & & & & \\
\hline \multicolumn{2}{|l|}{ Pre-op } & $1.2 \pm 0.5$ & 1.2 & $1.3 \pm 0.6$ & 1.3 & $0.723 \mathrm{~m}$ \\
\hline \multicolumn{2}{|l|}{ Post-op } & $1.2 \pm 1.0$ & 0.9 & $1.9 \pm 2.1$ & 1.0 & $0.264 \mathrm{~m}$ \\
\hline \multicolumn{2}{|c|}{$\begin{array}{l}\text { Preop-postop difference } \\
\text { In-group difference (p) }\end{array}$} & $\begin{array}{c}0.0 \pm 1.2 \\
0.201 \mathrm{w}\end{array}$ & 0.1 & $\begin{array}{c}-0.5 \pm 2.0 \\
0.950 \text { w }\end{array}$ & 0.0 & $0.381 \mathrm{~m}$ \\
\hline
\end{tabular}

in patients with solitary kidneys. In fact, even if it is not invasive, ESWL is characterized by the risk of complications that may affect renal function and may be risky in patients with solitary kidneys due to a lack of functional compensation by the contralateral kidney. Ureteral obstruction by residual stone fragments (steinstrasse), urinary tract infection and sepsis, asymptomatic renal hematoma, kidney nephron losses, may vary between 6$10 \%$ in total and may be a more important risk for patients with solitary kidneys (9).

While percutaneous nephrolithotomy (PCNL) is the first surgical option that can be considered for kidney stones larger than $2 \mathrm{~cm}$, RIRS is more preferred in patients with solitary kidney stones to prevent organ loss and greater risk of complications. In recent studies, complications like those of RIRS are described for miniaturized PCNL, which can be used instead of standard PCNL (10).

RIRS is an increasingly common and widely preferred procedure because of its high success rate for $1-3 \mathrm{~cm}$ kidney stones and its low complication rates (11-12). However, some minor complications, such as haematuria, hydronephrosis, ureteral obstruction by stone fragments and ureteral double J stent dislocation, might be not significant in a patient with two functional kidneys but could be more important for patients with solitary kidneys requiring urgent intervention.

Concern about the risk of renal dysfunction and subcapsular hematoma associated with the use of high-pressure irrigation during RIRS has been raised (13).

Animal studies have shown that high-pressure irrigation (> $150 \mathrm{mmHg}$ ) during ureterorenoscopy without a renal access sheath can lead to parenchymal damage and focal injury of the kidney (14). Therefore, this risk should be taken into consideration especially in patients with solitary kidney and renal access sheath should be used (15). Even if the success rate in the operations does not change, the use of urethral sheath is recommended, if possible, because it keeps the intrarenal pressure low during the procedure and reduces the risk of post-operative infection (16). We used a $9.5 \mathrm{~F}$ renal access sheath in all patients without pre-stenting. It has been shown that insert-

\section{Discussion}

Flexibility and thinning of endoscopic instrumentation have increased day by day for making more comfortable diagnosis and treatment of the urinary system.

Innovations in technology allowed improvement of ureteroscope design, surgical technique, and accessory instrumentation (8).

Although less invasive procedures have been developed for the treatment of kidney stones, the first procedure to be considered for certain types of stones is extracorporeal shock wave lithotripsy (ESWL), whose use is controversial ing a DJ stent before surgery does not affect complication or success $(17,18)$.

Performing RIRS should be more careful in patients with a solitary kidney stone. The application of access sheaths and use of laser should not harm the kidney or ureter and at the end of the procedure, it should be checked DJ stent correct placement $(3,7)$.

In our study surgery in solitary kidney was performed by experienced surgeons.

The mean stone size was $14 \pm 0.4 \mathrm{~cm}$, surgical success was $87.3 \%$ and 4 patients $(7.5 \%)$ had residual stones of 
more than $4 \mathrm{~mm}$. After all the procedures, DJ stents were applied and checked and left for the second session.

Classification systems have been proposed over time for grading complications that can develop during and after RIRS. We assessed complications using a modification of Satava Classification System (SCS) (19).

Ural et al. reported nearly 32\% grade 1 intraoperative complications after RIRS according to modified SCS. Grade 1 complications included minimal haematuria, ureteral mucosal surface damage, and difficulties in reaching the stone (20). Kuroda et al. reported a rate of minor complication about 5\% in a study comparing RIRS performed in solitary kidneys and normal patients (14). Atis et al. reported a rate of minor complications of $16.6 \%$ with no major complications and no need of blood transfusions (6).

In our study, 11 patients $(20.5 \%)$ had grade 1 minor complications (most of them mild haematuria that was observed in 8 patients) and no one needed for blood transfusion. DJ stent migration is especially troublesome in postoperative follow-up of patients with solitary kidney. Although DJ stents are known to cause post-operative irritating symptoms, they should be applied after RIRS especially in patients with solitary kidneys (21). Accordingly, we applied DJ stents to all patients at the end of the procedure. Grade 3-4 complications after RIRS can threaten the health of patients. Although they are rare in the literature, deficit of post-operative follow-up and patient unconsciousness can increase the importance of these complications $(22,23)$. Two of our patients developed postoperative high serum creatinine and oliguriaanuria after discharge. The first patient did not receive enough post-operative hydration causing a reduced urine output until oliguria developed. On postoperative day $4^{\text {th }}$, urine output and serum creatinine levels returned to normal with appropriate hydration.

The other patient presented with anuria on the $5^{\text {th }}$ postoperative day. He reported that his urine output had decreased and ceased for the last two days. Despite appropriate hydration, urine output did not increase, and serum creatinine values increased to around $8.9 \mathrm{mg} / \mathrm{dl}$.

The patient was urgently operated: after DJ stent removal, ureteroscopy demonstrated a dust of fragments adherent along the ureter, ureter was cleaned, and a new 6 F DJ stent was placed. Although postoperative urine output increased, serum creatine values did not fall below $4.3 \mathrm{mg} / \mathrm{dl}$.

After the consultation of the nephrology department, it was decided to enter in a dialysis program with the diagnosis of chronic renal failure. Although major complications after RIRS are not common in the literature, poor socioeconomic conditions can affect the post-operative recovery of the patients (3-7).

It has been reported that patients with solitary kidney have very low complication rates compared to percutaneous nephrolithotomy (PCNL) $(11,22)$. RIRS has been considered a better alternative to PCNL surgery because of similar surgical success, but less blood loss and hospital stay (24).

When we evaluated our patients, we observed that minor and major surgical complications increased significantly after surgery of stone greater than $20 \mathrm{~mm}$ and when surgery time was more than 60 minutes. (Table 3) Although
RIRS appears to be safe and successful in patients with solitary kidneys, the prolongation of surgery may lead to an increase of postoperative complications. We set the 60-minute limit although this limit can be influenced by the characteristics of the patient, of the stone and of the surgical procedure.

Patients with solitary kidneys should be well informed and followed up before and after surgery. When evaluating a patient, attention should be paid to the size of the stone and therefore to the risk of increased surgical time. For cases that are thought to exceed one hour, we recommend leaving a DJ stent for a second session.

\section{REFERENCES}

1. El-Assmy A, El-Nahas AR, Hekal IA, et al. Long-term effects of extracorporeal shock wave lithotripsy on renal function: our experience with 156 patients with solitary kidney. J Urol. 2008; 179:2229-32.

2. Ruiz Marcellan FJ , Ibarz Servio L, et al. Treatment of lithiasis in the patient with a solitary kidney Eur Urol. 1988; 15:13-7.

3. Bas O, Tuygun C, Dede O, et al. Factors affecting complication rates of retrograde flexible ureterorenoscopy: analysis of 1571 procedures-a single-center experience. World J Urol. 2017; 35:819-826.

4. Gao X, Peng Y, Shi X, et al. Safety and efficacy of retrograde intrarenal surgery for renal stones in patients with a solitary kidney: a single-center experience. J Endourol. 2014; 28:1290-4.

5. Breda A, Oreoluwa O, John $T$, et al. Flexible ureteroscopy and laser lithotripsy for multiple unilateral intrarenal stones Eur Urol. 2009; 55:1190-6.

6. Atis G, Gurbuz C, Arikan O, Kilic M, et al. Retrograde intrarenal surgery for the treatment of renal stones in patients with a solitary kidney. Urology. 2013; 82:290-4.

7. Giusti G, Proietti S, Cindolo L, et al. Is retrograde intrarenal surgery a viable treatment option for renal stones in patients with solitary kidney? World J Urol. 2015; 33:309-14.

8. Holden T, Pedro RN, Hendlin K, et al. Evidence-based instrumentation for flexible ureteroscopy: a review J Endourol. 2008; 22:1423-6.

9. Wagenius M, Jakobsson J, Stranne J, Linder A. Complications in extracorporeal shockwave lithotripsy: a cohort study. Scand J Urol. 2017; 51:407-413.

10. Di Mauro D, La Rosa VL, Cimino S, et al. Clinical and psychological outcomes of patients undergoing Retrograde Intrarenal Surgery and Miniaturised Percutaneous Nephrolithotomy for kidney stones. A preliminary study. Arch Ital Urol Androl. 2020; 91:256-260.

11. Zhang Y, Wu Y, Li J, et al. Comparison of percutaneous nephrolithotomy and retrograde intrarenal surgery for the treatment of lower calyceal calculi of $2-3 \mathrm{~cm}$ in patients with solitary kidney. Urology. 2018; 115:65-70.

12. Aboumarzouk OM, Monga M, Kata SG, et al. Flexible ureteroscopy and laser lithotripsy for stones $>2 \mathrm{~cm}$ : a systematic review and meta-analysis J Endourol. 2012; 26:1257-63.

13. De Rose AF, Di Grazia E, Magnano San Lio V, et al. Complications of endourological procedures and their treatment. Arch Ital Urol Androl. 2020; 92:321-325.

14. Schwalb DM, Eshghi M, Davidian M, et al. Morphological and physiological changes in the urinary tract associated with ureteral dilation and ureteropyeloscopy: an experimental study. J Urol. 1993; 149:1576-85. 
15. Breda A, Territo A, López-Martínez JM. Benefits and risks of ureteral access sheaths for retrograde renal access Curr Opin Urol. 2016; 26:70-5

16. Kuroda S, Fujikawa A, Tabei T, et al. Retrograde intrarenal surgery for urinary stone disease in patients with solitary kidney: A retrospective analysis of the efficacy and safety. Int J Urol. 2016; 23:69-73.

17. Shvero A, Herzberg H, Zilberman D, et al. Is it safe to use a ureteral access sheath in an unstented ureter? BMC Urol. 2019;19:80.

18. Karaaslan M, Tonyali S, Yilmaz M, et al. Ureteral access sheath use in retrograde intrarenal surgery. Arch Ital Urol Androl. 2019; 91:112-114.

19. Tepeler A, Resorlu B, Sahin T, et al. Categorization of intraoperative ureteroscopy complications using modified Satava classification system World J Urol. 2014; 32:131-6.

20. Oguz U, Resorlu B, Ozyuvali E, et al. Categorizing intraopera- tive complications of retrograde intrarenal surgery. Urol Int. 2014; 92:164-8.

21. Somani BK, Giusti G, Sun Y, et al. Complications associated with ureterorenoscopy (URS) related to treatment of urolithiasis: the Clinical Research Office of Endourological Society URS Global Study World J Urol. 2017; 35:675-681.

22. Cindolo L, Castellan P, Primiceri G, et al. Life-threatening complications after ureteroscopy for urinary stones: survey and systematic literature review Minerva Urol Nefrol. 2017; 69:421-431.

23. Adanur S, Aydin HR, Mohamed O, et al. Retrograde intrarenal surgey versus percutaneous nephrolithotomy in patients with signifcant comorbidities and solitary kidney Urolithiasis. 2015; 43:385-386.

24. Lianchao J, Bing Y, Zhe Z, Ningchen Li. Comparative efficacy on flexible ureteroscopy lithotripsy and miniaturized percutaneous nephrolithotomy for the treatment of medium-sized lower-pole renal calculi J Endourol. 2019; 33:914-919.

\section{Correspondence}

Bulent Kati, MD, Associate Prof. (Corresponding Author)

bulentkati@harran.edu.tr

Eyyup Sabri Pelit, MD

dreyyupsabri@hotmail.com

Mehmet Demir, MD

drdemir02@gmail.com

Ismail Yagmur, MD

dr_iyagmur@hotmail.com

Adem Tuncekin, MD

dr_adem65@hotmail.com

Halil Ciftci, MD

halilciftci63@hotmail.com

Harran University, Faculty of Medicine Hospital, Urology, 63340 Sanliurfa

(Turkey) Osmanbey Kampusu Urology Bolumu 63320 Sanliurfa (Turkey) 